\title{
Comentario sobre el libro de Ernesto Castillo Martínez, Ensayos y opiniones sobre la realidad nicaragüense
}

\section{Luis Rocha Urtecho*}

La profundización en aspectos económicos, políticos y sociales en diversas épocas de nuestra historia ha sido en Ernesto Castillo Martínez no únicamente una afición, sino una rigurosa devoción y hasta adicción, que lo ha llevado a utilizar con singular acierto diversos géneros, como el anecdótico, tan presente y ameno en los dos volúmenes de sus Historias no contadas o a medio contar (CNE, 1999), en los que emprende un recorrido que pareciera lindar con la ficción, que a manera de pequeñas narraciones cautivan al lector y lo inducen a un conocimiento más profundo de nuestra historia: a la lectura y análisis que todos debemos emprender para ir sacando conclusiones sobre si hemos aprendido algo útil para avanzar en este nuevo siglo, o si la historia se quedó inmóvil en el siglo anterior.

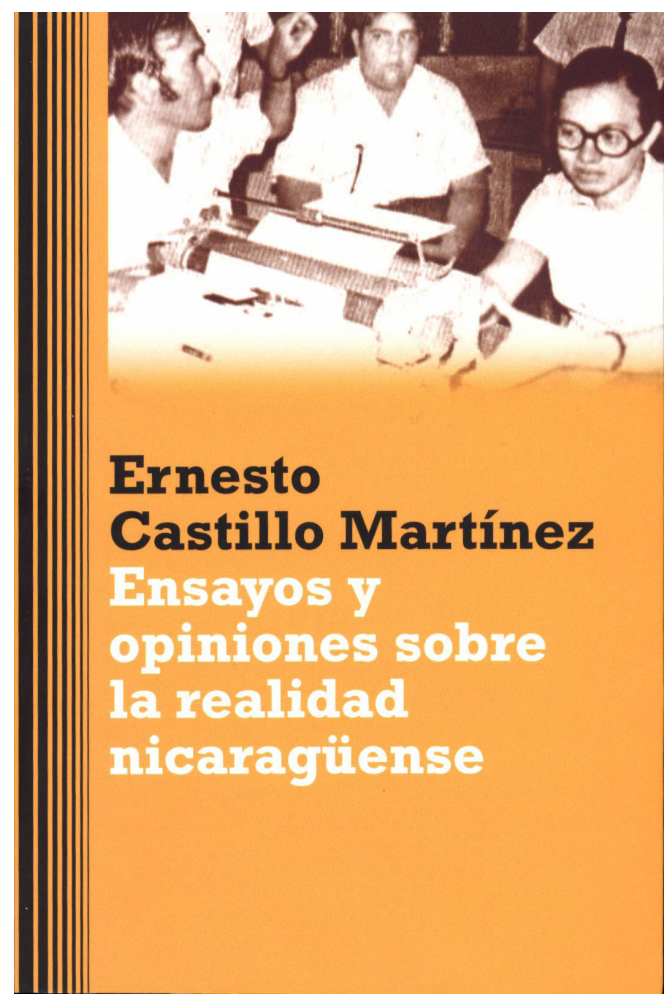

Otro género, dentro del contexto histórico al que nos referimos, es el epistolar, donde el autor asume la personalidad del Prof. José de la Cruz Pérez para escribirle, 
de manera respetuosa y didáctica, a la entonces presidenta, doña Violeta Barrios de Chamorro, en Mis Cartas a la Presidenta (CIRA, 2002), en las que hay un manejo magistral de la ironía. Durante la "nueva era" del presidente Enrique Bolaños, algo parecido quiso hacer al escribirle a la entonces primera dama, doña Lila T., para que aconsejara a don Enrique, pero desistió en el camino, y desde luego que ni intentó enviarle cartas al presidente Arnoldo Alemán, o a Daniel Ortega. Otros fueron los mensajes a dichos personajes, y sobre todo al pueblo nicaragüense, expresados en ensayos y opiniones en este libro, al que, como se ve, llega respaldado y enriquecido por los dos libros de historia citados, y por el ejercicio intelectual y literario de otros dos libros anteriores: Introducción al Derecho, que -dado el comportamiento de magistrados y jueces hoy en día- bien pudiera ser el primer volumen de su libro De ayer y de siempre, un texto sobre mitos y leyendas.

Ensayos y opiniones sobre la realidad nicaragüense, como lo explica el autor en su introducción, consta de dos secciones: ensayos y opiniones, ya que, como afirma Frances Kinloch en Identidad y Cultura Política: "Todo conocimiento histórico se construye sobre bases asentadas pacientemente por los estudiosos de nuestro pasado que nos han precedido en este oficio". Y en cuanto a la actualidad, sé que Tito -como periodistas que fuimos cuando publicábamos el semanario Testimonio- siempre ha sido un historiador en constante movimiento, y es por ello, por lo que aquí leo y por lo que hoy nos toca vivir, que siento como que estamos empantanados en la historia inmóvil de que hablaba. Somos, para el poder, ciudadanos sin categoría, al parecer irredentos, irredimibles e indefensos, a quienes históricamente, con una voracidad sin límites, nos engullen pactos, caudillos y dictadores. Porque la historia tiene también que moverse y ser fuente de aprendizaje para no seguir cometiendo, época tras época, los mismos errores, ya que el aprendizaje es sabiduría y libertad.

Actualmente, todo es como si la historia nos condujera en un remolino por la taza de un inodoro nacional que en vez de agua tiene horas, días y años, hacia el mismo hoyo, para volver a ascender otra vez y descubrir que, pese a tantas guerras, muertos, héroes y mártires, nos encontramos en el mismo punto de partida. Volvemos al hoyo del que creíamos haber salido, engañados o ahogados en nuestras propias ilusiones, junto con el propio José Coronel Urtecho en su esperanzado gran poema No volverá el pasado. Y el pasado volvió. En su Introducción a Reflexiones sobre la Historia de Nicaragua, del mismo Coronel Urtecho (Fundación Vida, 2001), Frances Kinloch escribió:

Cuando la historia se hace presente en la mentalidad de una nación, se vuelve un elemento vivo de su cultura. Por el contrario, la falta de ese acervo imprescindible, como cuadro de referencia, aumenta la desorientación individual y colectiva, no sólo sobre el pasado sino sobre los mismos problemas del presente.

En ese sentido, la intención de Ensayos y opiniones sobre la realidad nicaragüense es dar movimiento a la historia e inducirnos a salir del hoyo. Darnos un elemento vivo de nuestra cultura. En La justicia y el pensamiento de Xabier Gorostiaga -ensayo incluido en este libro- el inolvidable jesuita, cariñosamente llamado Pitorro, dice: 
Es posible (otro mundo), y lo vamos a hacer. Es decir, que no sólo es posible sino que es una necesidad y el gran reto es cómo, desde la gran diversidad, desde los distintos sectores se crea ese factor catalizador ... No usando el poder de las armas, sino el poder de la ética y la fraternidad. Ése es el gran reto.

Hace unos pocos años no podía imaginarme que otra Iglesia católica, por verdadera -como quienes dirigíamos Testimonio la concebíamos- podía ser posible. El Papa Francisco, que al decir de Ernesto Cardenal se ha convertido en párroco del mundo, hará profética la esperanza de Xabier Gorostiaga, y es posible que dicha profecía alcance a su Nicaragua: "Me enamoré de Nicaragua casi desde el primer momento y seguiré vinculado a mi nueva patria, no importa donde este errático destino de los designios de Dios me lleve...”. En ese texto, Xabier Gorostiaga nos plantea el reto de un diálogo global.

José María Valverde escribe en su Diccionario de Historia:

En conjunto, a lo que más aspira este diccionario es a sugerir que hoy en día la historia quiere ser 'global', incluyendo la economía, la manera de pensar, la ciencia, la técnica, los movimientos religiosos, la vida cotidiana con sus usos y consumos, las diferencias entre hombres y mujeres...

En su introducción, Tito nos invita "a examinar científicamente los hechos históricos”. ¿Pero cuál es la consecuencia de esta reflexión? Al respecto me permito citar el final del prólogo de Vida y muerte de las ideas, de José María Valverde: "A pesar de todo, no sacamos ninguna consecuencia pesimista ni optimista hacia el porvenir de la mente y la palabra, limitándonos a invocar la coplilla machadiana:

\section{Confiamos}

en que no será verdad

nada de lo que pensamos”.

Luis Rocha

"Extremadura”, Masatepe, 30 de enero de 2014.

\section{Adendum}

Releída la anterior presentación para el libro de Tito, me resulta agobiante comprobar, en la penumbra de nuestra historia actual, que no hemos llegado a nuevo siglo alguno; que la historia no únicamente se ha quedado inmóvil, sino que ha retrocedido y es producto de una deliberada involución incubada en la codicia, la corrupción y el mesianismo de quienes nos oprimen, y que ya ni siquiera podemos asirnos a la copla de Antonio Machado, porque ya no podemos confiar "en que no será verdad/ nada de lo que pensamos”. ¿Por qué? Ya lo dijo Gabriel Celaya: "Porque 
vivimos a golpes, porque/ apenas si nos dejan/ decir que somos quien somos, /... Estamos tocando el fondo".

Al hacer un examen científico de los hechos históricos de Nicaragua, tal y como pedía su autor, me encuentro que el propósito de este libro es encontrar una salida al caos imperante. Partiendo de ese postulado es obvio que una revisión crítica de nuestra historia siempre será actual, pues toda revisión o rectificación de los errores pasados no es potestad de caudillos, sino del pueblo: la historia nos pertenece y está por hacerse entre todos nosotros, los que vivimos a golpes, y que sí diremos quiénes somos. Pero eso sí, nunca como ahora la historia de nuestra patria se ha visto tan distorsionada e irrespetada, y nunca como ahora nuestra patria ha estado tan descaradamente puesta a la venta, y nunca como hoy tan impunemente las instituciones -en su momento pensadas en democracia para protegernos y defender nuestra soberanía- han sido tan desvirtuadas en su esencia, hasta convertir a sus directores en una especie de sicarios uniformados, comprometidos a perpetuar en el poder a una familia, y a luchar contra el pueblo para que se cumpla la voluntad de los poderosos.

Cuando el 23 de febrero de este 2015 Sergio Ramírez recibió el Premio Internacional Carlos Fuentes, al referirse a todos aquellos que en diferentes épocas fueron acogidos por México, dijo:

El general Sandino el primero de ellos, escritor a su manera, que iluminó en las hermosas palabras de sus cartas y manifiestos su hazaña de defender la soberanía de mi patria, tantas veces puesta en riesgo y tantas veces mancillada por potencias extranjeras, de un siglo a otro siglo; una historia que parece una rueda que gira cada vez bajo un nuevo impulso, para regresar siempre al mismo lugar. (...) Fui protagonista en mi patria de una revolución triunfante, y puedo decir que la de hoy no es una violencia que busca transformar la sociedad para hacerla más justa, sino una violencia criminal, para envilecerla. Pero tiene la misma raíz, porque se alimenta de la pobreza. Para entrar en el siglo veintiuno, debemos dejar atrás primero el siglo diecinueve.

Eldomingo pasado, en El Arenal (Masatepe), Mónica López Baltodano nos hizo una magistral exposición sobre la burla con alevosía y ventaja que ha sido el proyecto del canal interoceánico, desde su gestación amparada en las sombras de la ambición, y lo es actualmente emergiendo desde ese pantano sinuoso e incomprensible en donde se incuba. Decía Mónica que más de setenta mil campesinos y pobladores han protagonizado treinta marchas de protesta en diferentes partes del país, en tan solo cinco meses. Una más tendríamos que agregar, con la del domingo pasado en Punta Gorda, a la que asistieron ocho mil personas. En su "cartilla de la dignidad" -así llamo yo a su breve documento de imprescindible lectura que ella ha titulado "Diez verdades sobre la promesa del Gran Canal"- entre tantas verdades que no voy a cometer el abuso de resumir, ella dice:

El poder, concentrado en la figura de la pareja presidencial ha logrado imponer la opinión sumisa de que el Canal Interoceánico y su caporal, esta 
vez chino, trae consigo el mágico hechizo que pondrá fin a los problemas históricos del país. Desde hace dos años, diría yo, se puso en marcha un deliberado proceso de fetichización llamado el "Gran Canal Interoceánico". Trama de la intoxicación de la palabra y la comunicación, de aturdimiento y sumisión de conciencias, en esta Nicaragua convertida hoy, en una especie de "prisión invisible", sin muros, ni puertas.

Las diez verdades, razonadas una a una, constituyen un recorrido didáctico por nuestra tragedia. Algunos de quienes estaban en El Arenal expresaron su frustración y desesperación. Pero esa sensación, concluimos poco después, es el primer paso para no ser indiferentes. Este importante paso se logra también con la lectura del libro de Tito, pues como ya cité de Frances Kinloch, se hace presente la historia en nuestra mentalidad de nación, para que no aumente "la desorientación individual y colectiva, no sólo sobre el pasado sino sobre los mismos problemas del presente".

La historia nos está enseñando que debemos proteger nuestra existencia ciudadana, alcanzando la fraternidad de sabernos todos nicaragüenses, con el convencimiento, por ejemplo, de que gracias a que El Tule, Nueva Guinea, Ometepe, San Miguelito, Punta Gorda y todas las comunidades campesinas que no agachan la cabeza, y que precisamente por saber que estamos tocando el fondo, la levantan con la dignidad de los hombres libres, nunca seremos esclavos, nunca nos despojarán con argucias ni seremos desheredados de lo que nos pertenece.

Disculpen, pero esta nueva historia no aparece formalmente en el libro de Tito, pero ahí está en cuanto que ha sucedido y tenemos que aprender. Sucediendo lo que está sucediendo, no podía menos que referirme a este apocalipsis social, político, ecológico y cultural. Un apocalipsis que nos está forzando a evadirnos, cueste lo que cueste, de esta "prisión invisible" a que se refería Mónica, y que a no pocos los hace pensar en la guerra. Esa es la dura realidad. En mi caso, todavía espero que encontremos una forma colectiva de apostar por la civilización contra la barbarie; por una esperanza beligerante hecha realidad, contra el desconsuelo de quien se resigna. Es lo que concluyo y quiero, pero hasta temo que mi deseo sea pura retórica. Pero eso sí, diría, como dice Tito Castillo, que "Se trata pues, de recuperar para la inmensa mayoría de los nicaragüenses el derecho efectivo de no tener que vivir en condiciones que nos obliguen a ser menos hombres". Menos mujeres.

"Extremadura”, Masatepe, 2 de marzo de 2015. 